\title{
Lifetime Studies of Mo/Si and Mo/Be Multilayer Coatings for Extreme Ultraviolet Lithography
}

\author{
M. Wedowski, S. Bajt, J. A. Folta,
}

E. M. Gullikson, U. Kleineberg,

L. E. Klebanoff, M. E. Malinowski, and W. M. Clift

This paper was prepared for submittal to the 44th Annual Meeting of the International Symposium on

Optical Science, Engineering, and Instrumentation

Denver, Colorado

July 18-23, 1999

August 5, 1999

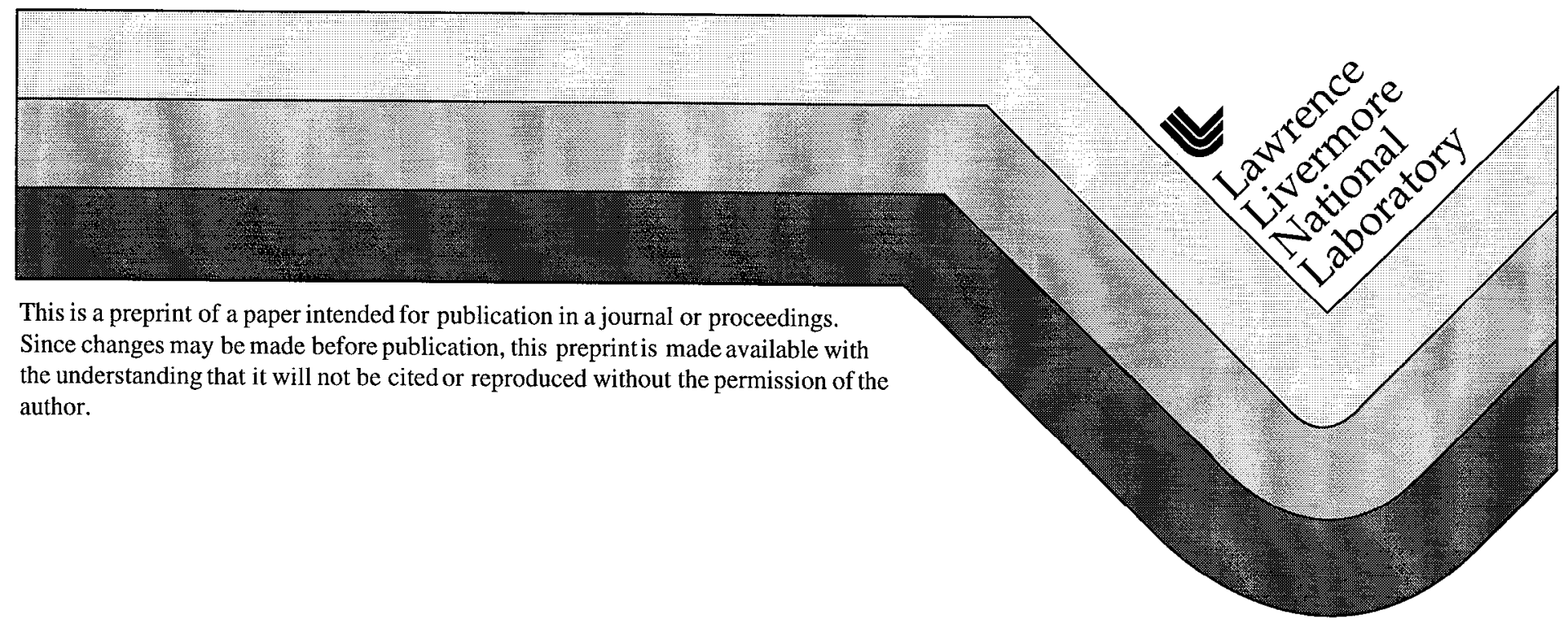




\section{DISCLAIMER}

This document was prepared as an account of work sponsored by an agency of the United States Government. Neither the United States Government nor the University of California nor any of their employees, makes any warranty, express or implied, or assumes any legal liability or responsibility for the accuracy, completeness, or usefulness of any information, apparatus, product, or process disclosed, or represents that its use would not infringe privately owned rights. Reference herein to any specific commercial product, process, or service by trade name, trademark, manufacturer, or otherwise, does not necessarily constitute or imply its endorsement, recommendation, or favoring by the United States Government or the University of California. The views and opinions of authors expressed herein do not necessarily state or reflect those of the United States Government or the University of California, and shall not be used for advertising or product endorsement purposes. 


\title{
Lifetime studies of Mo/Si and Mo/Be multilayer coatings for extreme ultraviolet lithography
}

\author{
Marco Wedowski, 'Saša Bajt, James A. Folta \\ Information Science \& Technology Program \\ Lawrence Livermore National Laboratory \\ P.O. Box 808, Livermore, California 94551 \\ Eric M. Gullikson, Ulf Kleineberg \\ Center for X-ray Optics \\ Lawrence Berkeley National Laboratory \\ One Cyclotron Road, Berkeley, California 94720 \\ Leonard E. Klebanoff, Michael E. Malinowski, W. Miles Clift \\ Materials Science \& Technology Department \\ Sandia National Laboratories \\ P.O. Box 969, Livermore, California 94551
}

\begin{abstract}
Extreme Ultraviolet Lithography (EUVL) is a candidate for future application by the semiconductor industry in the production of sub-100 $\mathrm{nm}$ feature sizes in integrated circuits. Using multilayer reflective coatings optimized at wavelengths ranging from 11 to $14 \mathrm{~nm}$, EUVL represents a potential successor to currently existing optical lithography techniques. In order to assess lifetimes of the multilayer coatings under realistic conditions, a series of radiation stability tests has been performed. In each run a dose of EUV radiation equivalent to several months of lithographic operation was applied to Mo/Si and $\mathrm{Mo} / \mathrm{Be}$ multilayer coatings within a few days. Depending on the residual gas concentration in the vacuum environment, surface deposition of carbon during the cxposurc lead to losses in the multilaycr reflectivity. However, in none of the experimental runs was structural damage within the bulk of the multilayers observed. Mo/Si multilayer coatings recovered their full original reflectivity after removal of the carbon layer by an ozone cleaning method. Auger depth profiling on $\mathrm{Mo} / \mathrm{Be}$ multilayers indicate that carbon penetrated into the Be top layer during illumination with high doses of EUV radiation. Subsequent ozone cleaning fully removed the carbon, but revealed enhanced oxidation of the area illuminated, which led to an irreversible loss in reflectance on the order of $1 \%$.
\end{abstract}

Keywords: Extreme ultraviolet (EUV) lithography, multilayer reflective coatings, radiation stability, surface contamination

\footnotetext{
* Correspondence: E-mail: wedowski@1lnl.gov; Telephone: 925-423-2830; Fax: 925-422-9628
} 


\section{INTRODUCTION}

High precision optical surfaces with soft $\mathrm{x}$-ray multilayer reflective coatings are key elements of any extreme ultraviolet lithography (EUVL) imaging system. These thin film coatings are specially designed for optimal performance under illumination with EUV radiation and their optical properties must remain unaltered under the radiation load throughout the lifetime of the system. Small field prototype EUVL systems using 2 mirrors in a Schwarzschild configuration have recently demonstrated the capability of printing sub-100 nm feature sizes with high quality', which made EUVL technology a leading candidate for future application by the semiconductor industry ${ }^{2}$. Within the current EUVL program efforts are underway in order to demonstrate the feasibility of full-field wafer exposures at a rate of $10+$ wafers per hour using a multi-mirror EUV optical design ${ }^{3}$. These production-like conditions will require unparalleled EUV radiation intensities and doses on the condenser as well as on the projection optics. In-band EUV power of $15 \mathrm{~W}$ and integrated doses of several hundred MJ during a full year of operation are projected in order to support production level wafer throughput. The cluster jet laser plasma source delivering these power levels is under development at Sandia National Laboratories ${ }^{4}$.

In order to assess stability of $\mathrm{Mo} / \mathrm{Be}$ and $\mathrm{Mo} / \mathrm{Si}$ multilayer reflective coatings during the lifetime of an EUVL optical system, several multilayer coatings have been exposed to undulator radiation at the Advanced Light Source (ALS) of the Lawrence Berkeley National Laboratory. Accelerating the experiments using intensities much higher than anticipated in an EUVL environment kept the individual exposure duration within a few days. Dose levels obtained are equivalent to EUVL-realistic conditions on the order of months to years of continuous exposure.

EUVL optical components need to be enclosed in a high vacuum environment in order to minimize absorption of EUV radiation by background gases during EUVL operation. This environment with a minimum pressure of $10^{-6}$ Torr together with the EUV illumination represents special conditions, which may influence the lifetime of multilayer-coated components. Factors anticipated to have an impact on the multilayer optical performance during EUVL operation are the residual gas composition as well as EUV radiation intensity and dose.

In particular hydrocarbons outgassing from the photoresist during the lithographic process have already been identified as potential sources of carbon deposition on EUV illuminated surfaces. Mitigation techniques using a gas curtain ${ }^{5}$ inside the EUVL optical system have been developed in order to prevent the hydrocarbons from reaching the optical surfaces. Other factors, which may influence the lifetime of EUVL optical components, include temperature effects, stress buildup and temporal stability of the multilayer coatings. These effects, which are not directly related to EUV radiation, have been investigated thoroughly ${ }^{6}$. Results are being considered in the design of the EUVL systems in order to minimize risks connected with these factors ${ }^{7}$.

\section{EXPERIMENTAL}

\subsection{Overall experimental approach}

Although carbon deposition on $x$-ray optical elements under exposure in general is a well-known effect, little information exists on the radiation hardness of multilayer coatings itself. A single publication reports about controlled exposures of $\mathrm{Mo} / \mathrm{Si}$ coatings to monochromatic undulator radiation ${ }^{8}$. No negative effect was observed after a 9-hour exposure at an average intensity of $0.75 \mathrm{~W} / \mathrm{cm}^{2}$. At the time of the experiment the corresponding dose was considered to simulate a one-year exposure of a hypothetical EUV component. However, in current EUVL optical designs an intensity of more than $1 \mathrm{~W}^{\mathrm{c}} \mathrm{cm}^{2}$ in-band EUV radiation is projected for some of the multilayer coated surfaces during normal operation. Therefore the earlier experiment simulated realistic conditions just for a few hours of EUV operation. $\Lambda$ s a consequence the main goal for this study is the search for effects possibly occurring at much higher doses. In a first step, several test multilayers were exposed under controlled vacuum and thermal conditions to a focussed spot of narrow-band EUV undulator radiation at the ALS interferometer beamline $12.0 .1^{9}$. In a second step, after the exposure changes in the optical performance of the multilayer coatings were probed at the ALS calibration and standards beamline 6.3.2 $2^{10}$. Full spatial mapping of the optical properties of multilayer coatings in the area exposed allows detection of variations with a spatial resolution of $0.1 \mathrm{~mm}$.

\subsection{Exposures at the ALS interferometry beamline 12.0.1}

ALS beamline 12.0.1 utilizes undulator radiation" and contains several optical components for spatial and spectral beam shaping. The higher spectral orders of the undulator are filtered to a large extent by grazing incidence reflection on the beamline optical components (Figure 1). The total EUV in-band power available for exposures is on the order of $50 \mathrm{~mW}$. 
Third order contamination is expected to be less than $10 \%$ with insignificant contributions of other higher orders. A Kirkpatrick-Baez mirror pair is used to focus the radiation near the sample. The spots exposed have a surface area on the order of $10^{-3} \mathrm{~cm}^{2}$ and therefore an intensity of up to $10 \mathrm{~W} / \mathrm{cm}^{2}$ can be delivered. Controlled vacuum conditions monitored by a residual gas analyzer were maintained by separating the exposure chamber from the rest of the beamline with a $0.1-\mathrm{mm}$ diameter aperture. The temperature of the sample, the sample photoemission current, and the storage ring current were monitored throughout the whole exposure time. Baking temperature of the vacuum chamber did not exceed 100 degrees $\mathrm{C}$ in order to reduce the risk of temperature-induccd effects on the sample. Temperature gradients occurring on the samples were thoroughly modeled and determined to be negligible for the purpose of the experiment. High thermal conductivity between the test wafer pieces and a copper heat sink was achieved by using an indium foil. The temperature rise observed during the exposure was on the order of a few degrees.

$\mathrm{Mo} / \mathrm{Si}$ exposures in the current study were performed on the M7 45-degree turning mirror, which is an integral part of end station 12.0.1.2. Therefore, in contrast to the Mo/Be exposures, there was no full control over the experimental parameters and only estimates on the doses and conditions of the $\mathrm{Mo} / \mathrm{Si}$ exposures can be made. These results may serve as an example for qualitative assessment of the radiation hardness of operational EUV Mo/Si multilayer coated optical components.

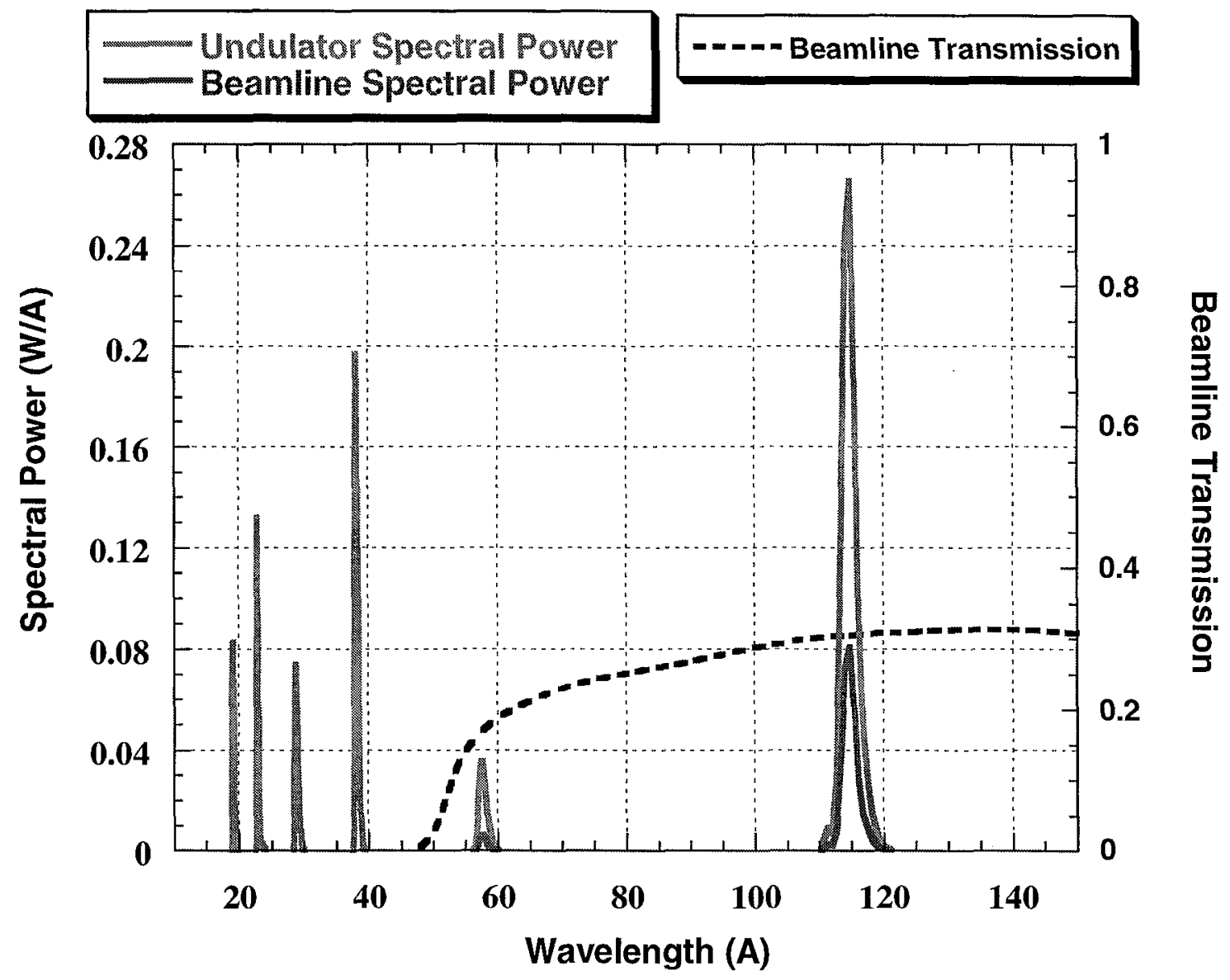

Figure 1: Modeled spectral power of ALS beamline 12.0.1 at the undulator and the beamline exit slit.

\subsection{EUV reflectometry at the ALS calibration and standards bcamline 6.3.2}

ALS beamline 6.3.2 utilizes bending magnet radiation ${ }^{10}$ for the characterization of the multilayer coatings after the exposure. The overall set-up includes a permanent high precision reflectometer end station. Experiments are controlled by a UNIX workstation using the LabView graphical programming language. Data evaluation is usually performed directly after the data acquisition using EXCEL and IDL software on a separate beamline PC. Careful selection of appropriate apertures, filters, and 
spectral order sorter settings together with full control over the measurement geometry allow high precision measurements of the multilayer reflectivity, wavelength centroid position and bandwidth. The precision limits of the respective parameters are listed in table 1. The parameters peak reflectance, wavelength centroid and bandwidth fully describe the optical properties of a multilayer coating relevant for EUVL purposes. Utilizing automatic procedures all three parameters can be routinely mapped across the surface of any multilayer coating up to $200 \mathrm{~mm}$ diameter including curved optics. Samples exposed in this study had diameters ranging from $10 \mathrm{~mm}$ to $25 \mathrm{~mm}$ and were characterized with high spatial resolution on the order of $0.1-\mathrm{mm}$ step sizc. Figure 2 shows a typical multilayer reflectance curve measured and evaluated at ALS bcamline 6.3.2.

\begin{tabular}{|c|c|}
\hline Peak reflectance & $0.2 \%$ \\
\hline Wavelength centroid & $0.02 \AA$ \\
\hline Bandwidth & $0.02 \AA$ \\
\hline
\end{tabular}

Table 1: Precision limits $(1 \sigma)$ in the characterization of optical properties of multilayer coatings at ALS beamline 6.3.2.

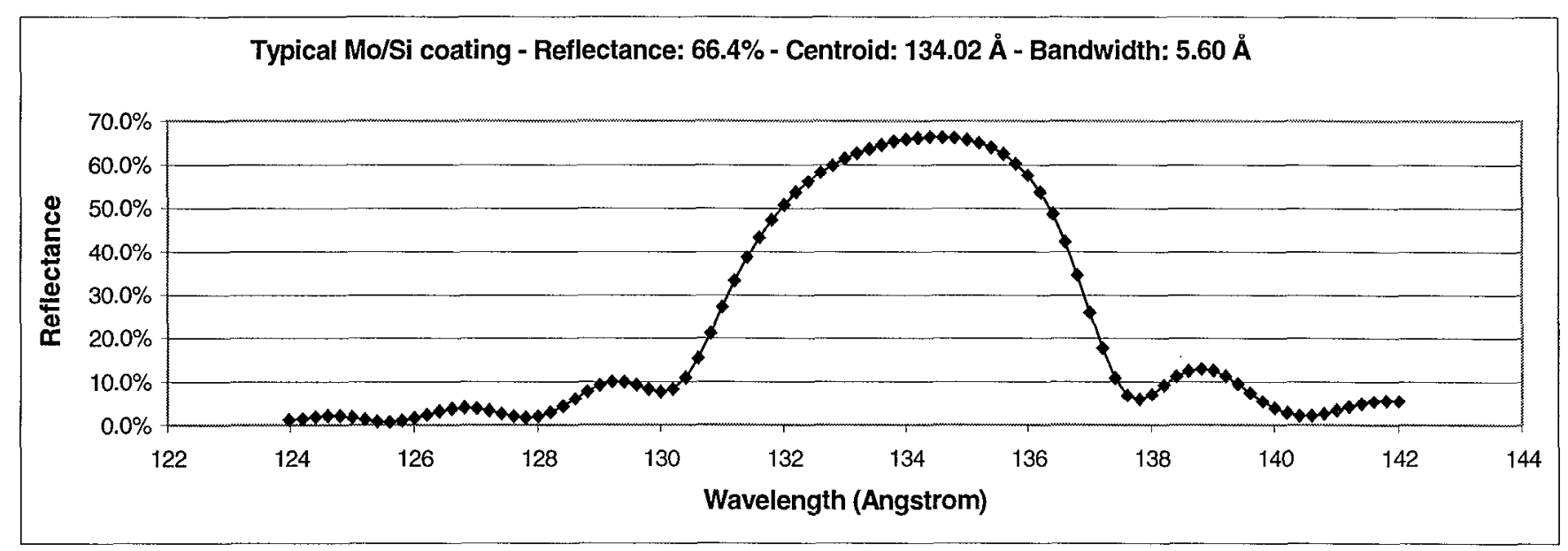

Figure 2: Typical reflectance curve of a Mo/Si multilayer coating obtained at ALS beamline 6.3.2.

\subsection{Sputter Auger analysis}

Sputter Auger analysis of exposed and unexposed areas of $\mathrm{Mo} / \mathrm{Si}$ and $\mathrm{Mo} / \mathrm{Be}$ multilayer coatings has been performed at Sandia National Laboratories. The qualitative chemical composition of contaminants on multilayer surfaces as well as the chemical structure of the bulk of multilayer coatings can be determined with this method. In addition secondary electron emission excited by an electron beam can be utilized for surface imaging of the areas exposed. However, the sputter crater produced during the sputter Auger analysis complicates any subsequent EUV reflectance measurements at the ALS due to partial removal of the multilayer top layer in the test spots exposed. Therefore the precision of EUV reflectance measurements in the remaining portion of the EUV illuminated spots after sputter Auger analysis is estimated to be on the order of $0.5 \%$.

\subsection{Ozone cleaning}

Ozone cleaning in commercial UV illumination systems, which produce ozone from atmospheric oxygen, is an established method for the removal of hydrocarbon contamination from grazing incidence optical surfaces at the ALS. In the current study ozone cleaning is used, first, for the removal of carbon contamination from multilayer coated surfaces and, second, for the assessment of the chemical reactivity of the multilayer top surface. For chemically reactive surfaces ozone cleaning may fully remove carbon contamination, however, afterwards it is impossible to distinguish between oxidation caused by the EUV illumination, oxidation due to the ozone cleaning process and oxidation due to atmospheric influences on the EUV illuminated spot after the exposure. 


\section{STRUCTURE OF MO/SI AND MO/BE MULTILAYER COATINGS}

$\mathrm{Mo} / \mathrm{Si}$ and $\mathrm{Mo} / \mathrm{Be}$ multilayer coatings reveal a very different structure in transmission electron microscope (TEM) cross sectional micrographs. In $\mathrm{Mo} / \mathrm{Si}$ multilayer coatings interdiffusion at the layer interfaces is more pronounced, while $\mathrm{Mo} / \mathrm{Be}$ has higher interfacial roughness. Also the chemical structure of the multilayer top layers is different in both systems. One top layer consists of a thin layer of silicon dioxide, while the other top layer consists of a three times thicker layer of beryllium oxide. In this study effects are searched for which may cause reduction of the lifetime of a multilayer coated optical system on the basis of the microscopic structure of the multilayer coating.

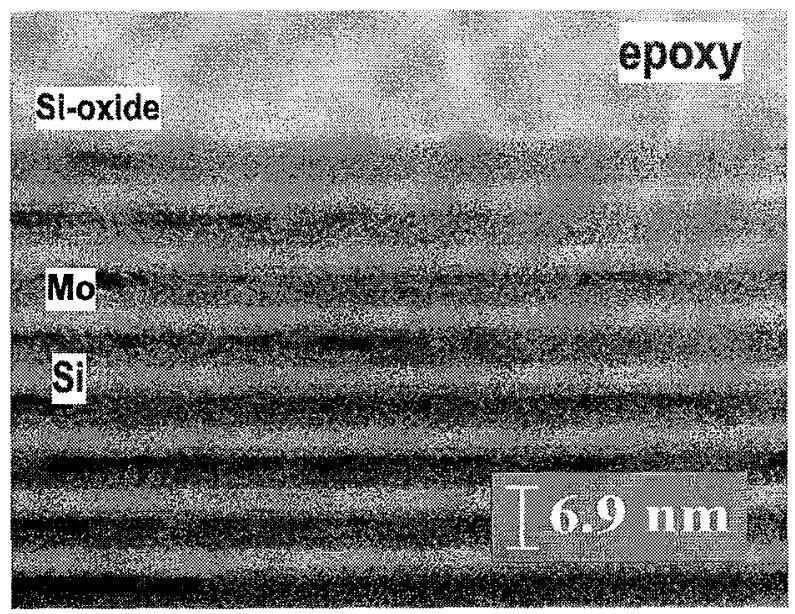

Figure 3: TEM cross section of the top region of a $\mathrm{Mo} / \mathrm{Si}$ multilayer. A typical coating consists of 40 bilayers. The silicon dioxide top layer is typically $1.3 \mathrm{~nm}$ thick.

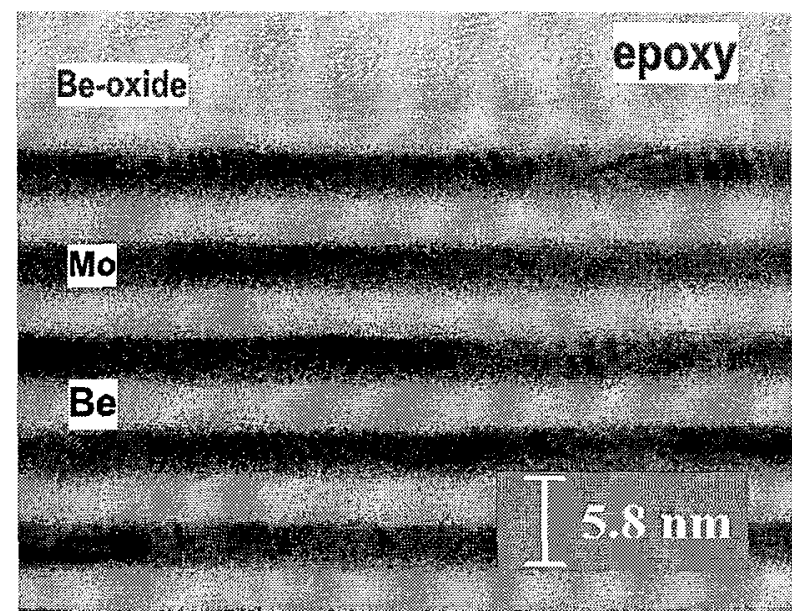

Figure 4: TEM cross section of the top region of a $\mathrm{Mo} / \mathrm{Be}$ multilayer. A typical coating consists of 70 bilayers. The beryllium oxide top layer is typically $3.5 \mathrm{~nm}$ thick.

\section{MO/BE MULTILAYER EXPOSURE}

\subsection{Exposure}

At a base pressure of $10^{-9}$ Torr containing $80 \%$ hydrogen, $10 \%$ water, small amounts of carbon dioxide and carbon monoxide, a $\mathrm{Mo} / \mathrm{Be}$ coated silicon wafer piece was exposed to narrow band EUV radiation with an average power of $35 \mathrm{~mW}$ for 40 hours. The spot illuminated had a size of $0.6 \mathrm{~mm}$ by $0.6 \mathrm{~mm}$ with an average intensity of approximately $10 \mathrm{~W} / \mathrm{cm}^{2}$ for a total dose of $1.4 \mathrm{MJ} / \mathrm{cm}^{2}$. During the exposure the relevant parameters were carefully controlled using methods described in the experimental section. In addition the beam shape and the EUV power were occasionally monitored using a phosphor screen and a calibrated photodiode, respectively.

\subsection{Results of the Mo/Be sample analysis after exposure}

Visual inspection with a microscope revealed no modification of the area exposed. Auger electron spectroscopy (AES) using a scanning electron beam after the exposure clearly identified increased carbon content near the center of the sample. The beam shape as observed with the phosphor screen coincides in a conclusive manner with a secondary electron emission map, an Auger electron map and an EUV reflectance map of the center portion of the sample. All three methods derive their contrast from modified material properties as compared to the surrounding area. The reflectance in the area exposed dropped from $66.6 \%$ to $64.4 \%$ without any indication of a shift in the wavelength centroid position or the bandwidth within the instrumental precision as listed in table 2. Ozone cleaning for 4 hours only partially recovered the full original reflectance. Enhanced oxidation of beryllium is probably responsible for this irreversible loss because after ozone cleaning just insignificant amounts of carbon could be detected by AES. On the basis of these observations it is concluded that carbon was deposited on the multilayer surface, but no damage to the bulk of the multilayer has occurred. Doses applied are equivalent to periods of months or years on different components of EUVL optical systems. The risk connected with radiation induced effects in the bulk of $\mathrm{Mo} / \mathrm{Be}$ multilayers is considered low. However, radiation-induced chemical surface reactions have revealed their potential of decreasing EUV rcflectance without damage to the multilayer structure itself. As a consequence multilayer coatings in EUVL, optical systems need to be protected against chemically reactive species in the vacuum. 


\subsection{Radiation induced surface chemistry}

Sputter Auger analysis results of the area exposed (Figure 5) indicate the formation of carbide in the beryllium top layer under the influence of EUV illumination. However, we cannot completely rule out that the carbide formation is an artifact of the sputter analysis process itself. Various independent methods support only the evidence of increased amounts of carbon in the exposed area. In any case the occurrence of carbide in the Auger electron spectra can be viewed as a general indication of chemical reactivity of the top layer of $\mathrm{Mo} / \mathrm{Be}$ multilayer coatings.

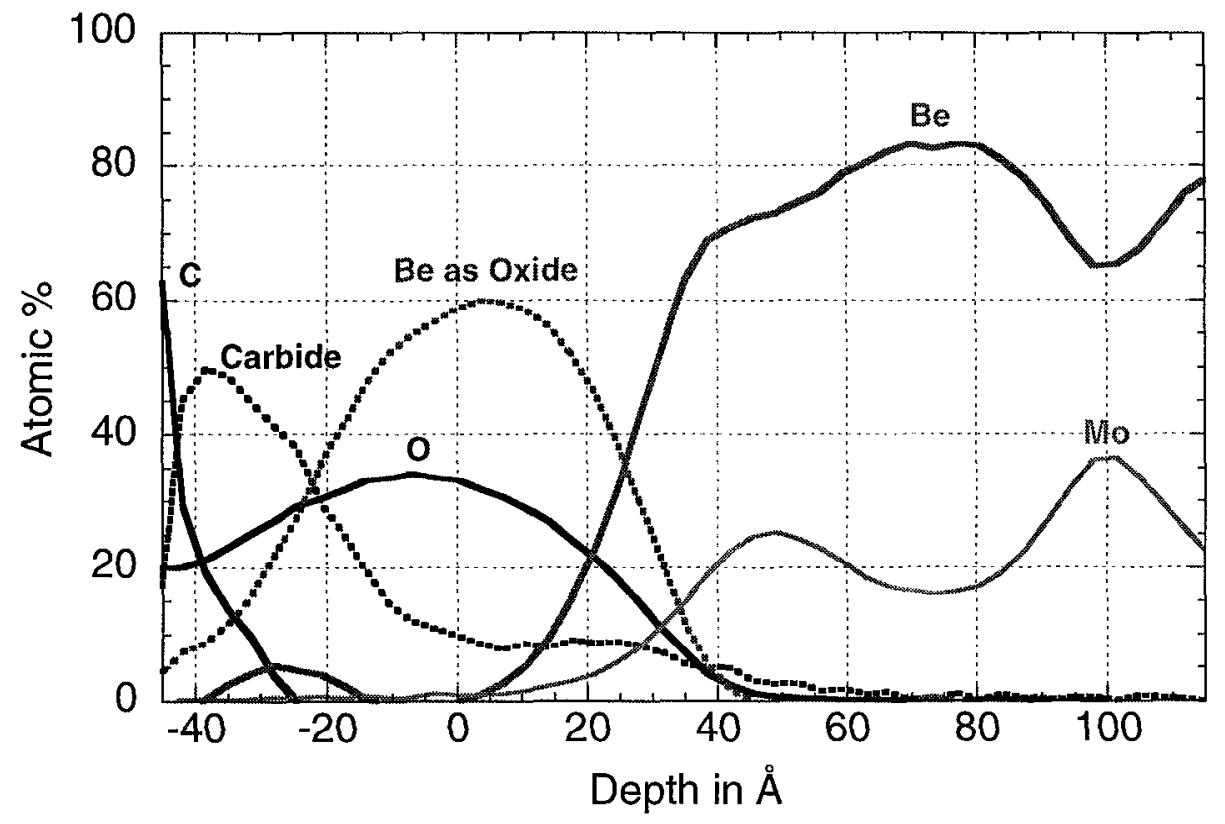

Figure 5: Sputter Auger depth profile of the EUV exposed area of a Mo/Be multilayer. Zero depth corresponds to the original multilayer surface before exposurc to atmospheric conditions after multilaycr deposition.

\section{MO/SI MULTILAYER EXPOSURE}

\subsection{Exposure}

Operation of the EUV interferometer at ALS beamline 12.0.1 requires the use of Mo/Si multilayer coated mirrors. Two such 45-degree "M7" turning mirrors were coated in 1997 and subsequently illuminated with the full EUV intensity at beamline 12.0.1 during operation of the interferometer. Both mirrors showed visible carbon contamination after regular use and were routinely rotated in order to illuminate less contaminated areas. The exposure duration on each of the remaining carbon spots is estimated to be 10 to 100 hours with variable vacuum conditions until the mirrors were replaced and ozone cleaned. Vacuum conditions were determined to be hydrocarbon rich, at a base pressure of approximately $10^{-7}$ Torr and average EUV intensities on the order of $1 \mathrm{~W} / \mathrm{cm}^{2}$. In summary, the conditions to which the $\mathrm{M} 7$ mirrors were exposed represent a worst case scenario for the operation of an EUVL optical system.

\subsection{Results of the Mo/Si sample analysis after exposure}

Upon ozone cleaning for 4 hours both mirrors recovered their original EUV reflectance of close to $50 \%$ uniformly throughout the whole surface without any indication for a shift in the centroid wavelength or bandwidth. Up to $190 \AA$ of carbon build-up had been measured with a profilometer before ozone cleaning.

\subsection{Radiation induced surface chemistry}

In contrast to $\mathrm{Mo} / \mathrm{Be}$ multilayer mirrors there is no indication for carbide formation on Mo/Si multilayer mirrors. EUV reflectance losses were observed on $\mathrm{Mo} / \mathrm{Si}$ multilayers exclusively due to carbon deposition on top of the silicon dioxide top layer. 


\section{CHEMICAL REACTIVITY OF MO/BE AND MO/SI MULTILAYER COATINGS}

The chemical reactivity of $\mathrm{Mo} / \mathrm{Be}$ and $\mathrm{Mo} / \mathrm{Si}$ multilayer coatings has been assessed by exposure to ozone for 24 hours and dipping in water for 5 minutes. Results are summarized in table 2.

\begin{tabular}{|c|c|c|}
\hline & water $(5 \mathrm{~min})$ & ozone $(24 \mathrm{~h})$ \\
\hline $\mathrm{Mo} / \mathrm{Be}$ & $>10 \%$ loss & $4 \%$ loss \\
\hline $\mathrm{Mo} / \mathrm{Si}$ & no change & no change \\
\hline
\end{tabular}

Table 2: Reflectance loss of $\mathrm{Mo} / \mathrm{Be}$ and $\mathrm{Mo} / \mathrm{Si}$ multilayers after ozone exposure and water dipping.

Mo/Si multilayer coatings are very robust systems during exposures to water and ozone. The properties of the top silicon dioxide layer provide sufficient protection against these chemicals under standard conditions. In contrast Mo/Be multilayer coatings are clearly more affected and show detectable degradation of their EUV reflectance.

\section{CONCLUSION}

No radiation-induced bulk-damage cffects were observed on $\mathrm{Mo} / \mathrm{Si}$ or $\mathrm{Mo} / \mathrm{Be}$ multilayers at practical doses of EUV radiation. However, contamination of the multilayer top surface may cause EUV reflectance losses depending on the environmental conditions. Contamination on $\mathrm{Mo} / \mathrm{Be}$ multilayers is partially irreversible due to chemical reactions on the multilayer surface.

\section{ACKNOWLEDGMENTS}

The authors thank John Bowers, Jim Underwood, Ken Goldberg, Patrick Naulleau, Jeff Bokor, Dave Attwood, Eric Ziegler, and Raul Beguiristain from the Center for X-ray Optics at the Lawrence Berkeley National Laboratory for providing support for this work.

This work was performed in part under the auspices of the U. S. Department of Energy by the Lawrence Livermore National Laboratory under Contract No. W-7405-ENG-48. Funding was provided by the Extreme Ultraviolet Limited Liability Company (EUV LLC) under a Cooperative Research and Development Agreement.

This work, performed in part at Sandia National Laboratories, is supported by the Extreme Ultraviolet Limited Liability Company (EUV LLC) and by the U.S. Department of Energy under contract DE-AC04-94AL85000.

\section{REFERENCES}

1. J.E.M.Goldsmith, K.W.Berger, D.R.Bozman, G.F.Cardinale, D.R.Folk, C.C.Henderson, D.J.O'Connell, A.K.RayChaudhuri, K.D.Stewart, D.A.Tichenor, H.N.Chapman, R.J.Gaughan, R.M.Hudyma, C.Montcalm, E.A.Spiller, J.S.Taylor, J.D.Williams, K.A.Goldberg, E.M.Gullikson, P.Naulleau, J.L.Cobb, "Sub-100-nm imaging with the EUV 10x microstepper" in Emerging Lithographic Technologies III, Yuli Vladimirski, Editor, Proceedings of SPIE Vol. 3676, 264271(1999).

2. Sematech Next Generation Lithography (NGL) Technology Review, June 9, 1999, Chicago, Illinois.

3. D.W.Sweeney, R.Hudyma, H.N.Chapman, David Shafer, "EUV Optical Design for a $100 \mathrm{~nm}$ CD Imaging System" in Emerging Lithographic Technologies II, Yuli Vladimirski, Editor, Proceedings of SPIE Vol. 3331, 2-10(1998).

4. G.D.Kubiak, L.J.Bernadez, K.Krenz, W.C.Sweatt, "Scale-up of a cluster jet laser plasma source for extreme ultraviolet lithography" in Emerging Lithographic Technologies III, Yuli Vladimirski, Editor, Proceedings of SPIE Vol. 3676, 669678(1999). 
5. M.P.Kanouff, A.K.Ray-Chaudhuri, "A gas curtain for mitigating hydrocarbon contamination of EUV lithographic optical components" in Emerging Lithographic Technologies II, Yuli Vladimirski, Editor, Proceedings of SPIE Vol. 3676, 735742(1999).

6. P.Mirkarimi, "Stress, reflectance, and temporal stability of sputter-deposited $\mathrm{Mo} / \mathrm{Si}$ and $\mathrm{Mo} / \mathrm{Be}$ multilayer films for extreme ultraviolet lithography", Opt.Eng. 38(7), 1246-1259 (1999) and references therein.

7. A.K.Ray-Chaudhuri, S.E.Gianoulakis, P.A.Spence, M.P.Kanouff, C.D.Moen, "Impact of thermal and structural effects on EUV lithographic performance" in Emerging Lithographic Tcchnologics II, Yuli Vladimirski, Editor, Proceedings of SPIE Vol. 3331, 124-132(1998).

8. D.Gaines, R.C.Spitzer, N.M.Ceglio, M.Krumrey, G.Ulm, "Radiation hardness of molybdenum silicon multilayers designed for use in a soft x-ray projection lithography system", App.Opt. 32, 6991-6998(1993).

9. D.Attwood, G.Sommargren, R. Beguiristain, "Undulator radiation for at-wavelength interferometry of optics for extremeultraviolet lithography", Appl.Opt. 32, 7022-7031(1993).

10. J.H.Underwood, E.M.Gullikson, "Beamline for measurement and characterization of multilayer optics for EUV lithography" in Emerging Lithographic Technologies II, Yuli Vladimirski, Editor, Proceedings of SPIE Vol. 3331, 5261(1998). 